\title{
PENGARUH SUASANA TOKO, LOKASI DAN PROMOSI TERHADAP MINAT BELI DI TOKO ROTI MORNING BAKERY
}

(Studi Pada Toko Roti Morning Bakery Batu 8 Jl. Raya Dompak Tnajungpinang)

\author{
raja hardiansyah \\ Jurusan Manajemen Sekolah Tinggi Ilmu Ekonomi (STIE) Pembangunan Tanjungpinang \\ rajahardiansyah@yahoo.co.id
}

\begin{abstract}
This study aims to find out the atmosphere of shop, location and promotion to cunsument buying interest in Morning Bakery Batu 8 Tanjungpinang city. This research is a survey using questionnaire as its instrument. Population used in this research is consument of Morning Bakery Batu 8 Tanjungpinang City the sample used ware morning Bakery Batu 8 Tanjungpinang City which amounted to people by using Purposive Sampling method. Instrument validity test using Corfirmatory Faktor Analysis and test of Reliability using Alpha Croanbach. The analysis technic used is multiplt linear analysis. Result of research found that Stote Atmosphare (X1) have positive effect to buying interest, Location (X2) have positive effect to buying interest, Promotion (X3) have positive effect. The amount of influence of the Atmosphere Store, Location and Promotion on interest buy (adjust $R$ ) is equal to 0,561.
\end{abstract}

Keywords : Store Astmosphere, Location and Promotion

\begin{abstract}
ABSTRAK
Penelitian ini bertujuan untuk mengetahui pengarus Suasana Toko, Lokasi dan Promosi Terhadap Minat Beli Konsumen di Toko roti Morning Bakery Batu 8 Kota Tanjungpinang. Penelitian ini merupakan penelitian survey dengan menggunakan kuesioner sebagai instrumenya. Populasi yang digunakan dalam penelitian ini adalah konsumen toko Roti Morning Bakery Batu 8 Kota Tanjungpinang. Sampel yang digunakan adalah konsumen Toko Roti Morning Bakery Batu 8 Kota Tanjungpinang yang berjumlah 50 orang dengan menggunakan metode Purposive Sampling. Uji validitas instrument menggunakan Penelitian Corfirmatory factor Analysis dan uji reabilitas menggunakan Alpha Cronbach. Teknik analisis yang digunakan adalah analisis linear berganda. Hasil penelitian menemukan bahwa Suasana Toko (X1) berpengaruh positif terhadap minat beli, Lokasi (X2) berpengaruh positif terhada minat beli, Promosi (X3) berpengaruh positif terhadap minat beli. Besarnya pengaruh Suasana Toko, Lokasi dan Promosi Terhadap Minat Beli (adjust R) adalah sebesar 0,561.
\end{abstract}

Kata kunci Suasana toko, lokasi dan Promosi

\section{PENDAHULUAN}

Pada setiap usaha bertujuan untuk mendapatkan keuntungan ataupun laba yang maksimal guna untuk mempertahankan keberadaan usaha di tengah persangingan yang makin sulit dan semakin ketat. Perusahaan harus mampu memenuhi kebutuhan dan keinginan konsumen agar dapat mencapai tujuan awal perusahaan.
Peningkatan akan adanya kegiatan konsumen di jaman semodern ini mengakibatkan ketatnya persaingan dalam bisnis ini. Dalam hal ini pembisnis maupun pengusaha di tuntut untuk mampu meaksimalkan kinerja usahanya agar daper bersaing di pasaran. Perusahaan harus berusaha keras untuk mempelajari dan memahami kebutuhan dan keinginan pelanggannya. 


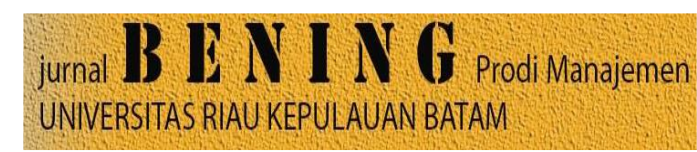

Melihat kondisi persaingan yang semakin ketat, setiap bisnis ritel modern perlu meningkatkan kekuatan yang ada dalam perusahaannya dengan cara menciptakan inovasi-inovasi baru atau keunikan yang dapat menarik minat beli konsumen terhadap produk yang di pasarkan.

Minat beli merupakan suatu yang berhubungan dengan rencana konsumen dalam membeli suatu produk tertentu serta berapa banyak produk tersebut yang akan di beli maupun di butuhkan oleh konsumen tersebut dalam periode tertentu. Menyikapi hal ini, perusahaan yang bermain di bisnis ini dituntut untuk selalu melakukan inovasi supaya minat beli konsumen tetap terjaga dan semakin meningkat. Dalam menarik minat beli konsumen dapat dilakukan dengan cara lain diantaranya memberikan suasana toko yang menyenangkan bagi kosumen, memiliki produk yang berkualitas, harga yang brsahabat, memberikan promosi seperti papan nama, diskon ataupun doorprize dan lokasi toko yang mudah diakses dan yang lainnya.

Suasana toko adalah suatu desain interior dimana dari karakteristik fisik toko seperti arsitektur, tata letak, pencahayaan, pemajangan, temperatur, musing hingga aroma yang menyeluruh akan menciptakan suasana yang nyaman bagi di benak konsumen. Setiap toko mempunyai tata desain interior yang memudahkan atau menyulitkan pembeli untuk berputar-putar didalamnya. Toko harus membentuk suasana terencana yang sesuai dengan pasar sasarannya dan dapat menarik konsumen untuk membeli. dengan begitu kosumen dapat mudah mengakses dengan adanya tata letak toko yang strategis.

Lokasi merupakan tempat dimana konsumen lebih mudah dalam menjangkau dan juga membuat konsumen mudah
Volume 6 No. 1 Tahun 2019

P-ISSN 2252-5262

E-ISSN 2614-499

mengingat lokasi tersebut. Dengan demikian, hubungan antara lokasi yang strategis dengan daya tarik konsumen untuk melakukan pembelian suatu produk. Jika lokasi sulit untuk di temukan bagi konsumen makan konsumen akan malas untuk mengunjungi usaha yang dijalankan. Dengan demikian lokasi juga berpengaruh bagi setiap bisnis udsaha yang di jalankan.

Promosi merupakan suatu usaha dimana untuk mengenalkan suatu produk di benak konsumen. Promosi juga sebagai tahap awal perkenalan bagi perusahaan antara produk yang dipasarkan sehingga konsumen dapat mengetahui jenis produk apa yang dipasarkan oleh perusahaan.

Oleh sebab itu,yang menjadi objek penelitian ini merupakan salah satu tempat toko konsumsi makanan yang ada di Tanjungpinang yaitu toko Roti Morning Bakery yang berlokasi di jalan Raya Dompak Km 8 Kota Tanjungpinang. Morning Bakery merupakan toko Yang menjual berbagai jenis produk roti yang dipadukan dengan tempat santai untuk sarapan maupun istirahat makan siang usaha tersebutpun mempunyai konsep yang disebut dengan open kitchen dimana konsumen dapat langsung melihat proses pembuatan roti secara langsung. Agar berhasil dalam memenangkan persaingan, Morning Bakery harus dapat menjaring konsumen sebanyak-banyaknya. Dengan kata lain perusahaan harus dapat menarik minat beli konsumen agar konsumen tersebut menjadi pelanggan yang loyal berkunjung di Mornng Bakery tersebut.

\section{Rumusan Masalah}

1. Apakah suasana toko terdapat pengaruh terhadap minat beli konsumen di Toko Roti Morning Bakery? 


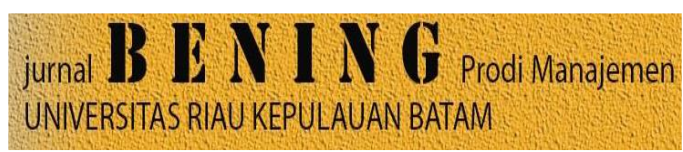

2. Apakah lokasi terdapat pengaruh terhadap minat beli konsumen di Toko Roti Morning Bakery?

3. Apakah promosi terdapat pengaruh terhadap minat beli konsumen di Toko Roti Morning Bakery?

\section{Tujuan Penelitian}

1. Untuk mengetahui pengaruh suasana toko terhadap minat beli konsumen di di Toko Roti Morning Bakery.

2. Untuk mengetahui pengaruh lokasi terhadap minat beli konsumen di Toko Roti Morning Bakery.

3. Untuk mengetahui pengaruh promosi terhadap minat beli konsumen di toko Roti Morning Bakery.

\section{TINJAUAN PUSTAKA}

\section{Pengertian suasana toko}

Suasana toko merupakan bagian dari salah satu yang memiliki arti penting dalam bisnis berwirausaha. Dengan adanya suasana toko yang baik, maka akan menarik pengunjung dan melakukan pembelian.

Suasana toko adalah karakteristik fisik yang sangat penting bagi setiap bisnis rite hal ini berperan sebagai penciptaan suasana yang nyaman sesuai dengan keinginan konsumen dan membuat konsumen ingin berlama-lama berada didalam sebuah toko dan secara tidak langsung merangsang konsumen untuk melakukan pembelian menurut Purnama (2011:62).

Dengan begitu minat beli konsumen akan selalu meningkat karena adanya suasana toko yang membuat nyaman dan betah yang selalu ingin membuat palanggan tersebut betah dan ingin berlama-lama di dalam sebuah toko.

\section{Pengertian Promosi}

Promosi adalah aktivitas yang mengkomunikasikan keunggulan produk dan membujuk pelanggan untuk membeli
Volume 6 No. 1 Tahun 2019

P-ISSN 2252-5262

E-ISSN 2614-499

produk tersebut menurut Kotler dan Amstrong (2014:77). Artinya promosi suatu usaha untuk menarik minat beli konsumen untuk membeli produk yang di tawarkan oleh perusahaan.

Promosi yaitu kegiatan yang bertujuan untuk meyampaikan informasi mengenai produk atau jasa kepada pasar, sehingga produk atau jasa tersebut dapat dikenal dan mendorong konsumen untuk membeli serta menggunakannya. Promosi juga sangat berguna untuk memberikan informasi mengenai kelebihan, kegunaan produk dan dimana produk tersebut dapat diperolehnya.

\section{Pengertian Lokasi}

Dalam memilih lokasi kita harus melihat dari segi pasar apakah ramai di lewati apakah sepi di lewati. Karena lokasi merupakan salah satu bagian dari pemasaran yang memiliki dampak yang cukup besar. Dalam hal ini perusahaan dituntut untuk mampu memilih lokasi yang strategis yang mudah dijangkau oleh masyarakat.

Menurut Heizer (2006:112) tujuan strategi lokasi adalah untuk memaksimalkan keuntungan lokasi bagi perusahaan. Keputusan lokasi sering bergantung kepada tipe bisnis. Pada analisis lokasi di sektor industri strategi yang dilakukan terfokus pada minimisasi biaya, sementara pada sektor jasa, fokus ditujukan untuk memaksimalkan pendapatan.

\section{Pengertian Minat Beli}

Minat beli adalah suatu yang timbul setelah menerima rangsangan dari produk yang di lihatnya, dari sana timbul ketertarikan untuk mencoba produk tersebut sampai akhirnya timbul keinginan untuk membeli agar dapat merasakan dari produk tersebut. Jadi setiap kegiatan usaha kita harus selalu membuat bagaimana konsumen agar tertarik dengan produk kita apakah 


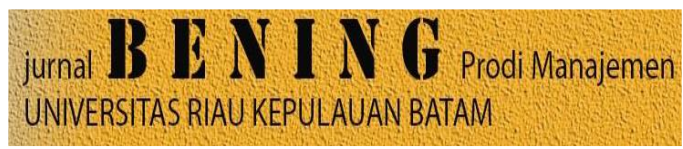

dengan cara promosi ataupun dengan cara membuat suatu produk yang unik dan inovatif.

Minat beli merupakan rasa ketertarikan yang dialami oleh pelanggan terhadap suatu produk (barang atau jasa) yang dipengaruhi oleh sikap diluar konsumen dan di dalamnya konsumen itu sendiri (Ashari, 2012:246). Sedangkan menurut Hidayat, Elita, dan Setiaman (2012:68) minat beli adalah sesuatu yang timbul setelah menerima rangsangan dari produk yang dili hatnya, dari sana timbul ketertarikan untuk mencoba produk tersebut sampai pada akhirnya timbul keinginan untuk membeli agar dapat untuk memilikinya.

\section{Kerangka pemikiran}

Konsumen untuk membeli produk yang ditawarkan, jika sebuah toko menawarkan promosi yang gencar akan menuhbuhkan minat beli para konsumen itu sendiri. Lokasi yang strategis lebih menguntungkan pengusaha dalam mengembangkan usahanya, semakin strategis lokasi sebuah toko ataupun usaha akan lebih menumbuhkan minat beli konsumen tersebut. karena lokasi yang mudah di tempuh dan tidak sulit mencarinya.

Suasana toko, lokasi dan promosi di rancang oleh pemilik toko untuk dapat menarik perhatian konsumen. Jika suasana toko sudah tertata baik dan membuat nyaman pengunjung dan ingin berlamalama dalam sebuah toko, lalu adanya lokasi yang mudah di akses dan di jangkau oleh konsumen serta promosi yang begitu inovativ, unik dan baik sehingga membuat konsumen semakin puas, maka akan menumbuhkan minat beli $\mathrm{di}$ benak pelanggan. Dan keuntungan yang di dapat perusahaan akan terpenuhi.
Volume 6 No. 1 Tahun 2019

P-ISSN 2252-5262

E-ISSN 2614-499

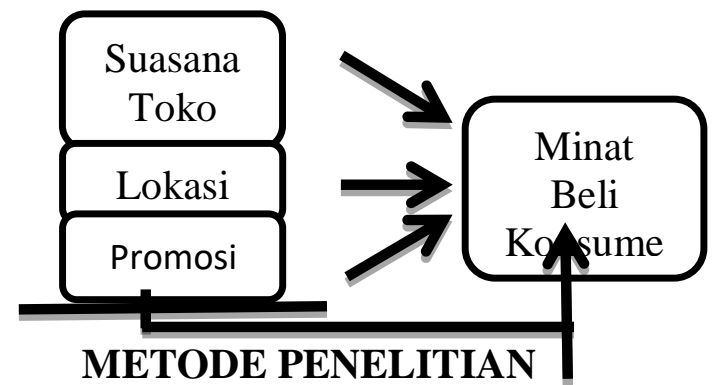

Identifikasi Variabel Penelitian Variabel independen pada penelitian ini adalah suasana toko (X1), promosi (X2) dan lokasi (X3). Variabel dependen pada penelitian ini adalah Minat pembelian (Y).

\section{Teknik dan Pendekatan Penelitian}

Teknik penelitian yang digunakan dalam penelitian ini yaitu korelasi, peneitian dengan korelasi merupakan penelitian yang dimaksudkan untuk mengukur tingkat kedekatan hubungan antar variabel-variabel menurut Reksoatmodjo (2007:129).

Pendekatan penelitian ini adalah pendekatan kuantitatif. Menurut Sugiyono (2010: 13) adalah data yang dinyatakan dalam bentuk angka-angka dan dapat dinyatakan dalam satuan hitung dan analisis menggunkan statistik.

\section{Populasi dan Sampel}

Populasi merupakan wilayah generalisasi yang terdiri dari objek atau subjek yang menjadi kuantitas dan dan karakteristik tertentu yang diterapkan oleh peneliti untuk dipelajari dan kemudian dirakit kesimpulannya Sugiono (2010:117). Populasi dalam penelitian ini adalah semua pelanggan Toko Roti Morning Bakery Batu 8 Kota Tanjungpinang. Menurut Sugiyono (2012: 81) "sampel adalah bagian dari jumlah dan karakteristik yang dimiliki oleh populasi tersebut". dengan jumlah sampel yang diambil sebanyak 50 responden. 


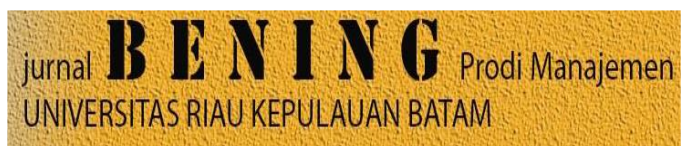

Kuesioner, dipergunakan untuk memperoleh data ordinal yang merupakan penjabaran dari indikator variabel. Kuesioner yang digunakan akan menggunakan skala likert yang mepunyai code atau score dalam menganalisanya. Sangat tidak seteju (1) tidak setuju (2) kurang setuju (3) setuju (4) sangat setuju (5). Sebelum digunakan untuk mengumpulkan data di lapangan terlebih dahulu harus diuji tingkat validitas dan reabilitasnya.

\section{Teknik Pengumpulan Data}

Dalam penelitian ini peneliti hanya menggunakan cara kuesioner, sehingga cara yang dipakai dalam pengumpulan data pada penelitian ini yaitu kuisioner dan penelitian kepustakaan.

\section{Validasi Instrumen}

1. Uji Validitas, merupakan suatu ukuran yang menunjukkan tingkattingkat kevalidan atau kesakhihan suatu instrumen (Sugiyono, 2011:455)

2. Uji Reliabilitas, merupakan alat untuk mengukur suatu kuesioner yang merupakan indikator dari suatu variabel (Sugiyono, 2011:458).

\section{Pengumpulan Data}

Penelitian ini menggunakan dua jenis data yaitu primer dan skunder. Data primer diperoleh dari penyebaran kuesioner tentang penilaian atau persepsi tentang suasana toko, lokasi dan promosi terhadap minat beli konsumen pada toko Roti Morning Bakery di Batu 8 di Kota Tanjungpinang. Sedangkan data sekunder diperoleh dari pihak manajemen pengelolah, selain itu didapat juga dari literature seperti buku, media elektronik atau internet dan sumber-sumber yang menunjang dalam penelitian.
Volume 6 No. 1 Tahun 2019

P-ISSN 2252-5262

E-ISSN 2614-499

\section{TEKNIK DAN ANALISIS DATA}

Teknik analisis data merupakan sub bab yang mengemukakan cara menganalisis data penelitian, termasuk alat-alat statistic yang bisa dan relavanyang di gunakan dalam penelitian ini menurut Rumengan (2010:137). Untuk itu data yang di ambil merupalan data kuantitatif yang diolah lalu di jabarkan untuk mengetahui hasil tersebut.

Analisis data kuantitatif merupakan analisis yang menggunakan bantuan statistic untuk membantu dalam penelitian dalam perhitungan maupun mengolah data untuk menganalisis data yang di peroleh. Analisis kuantitatif ini dapat digunakan terhadap data yang berwujud angka-angka dan cara pembahasannya. Dalam hal ini penelitian menggunakan program SPSS For Windows versi 21.

Analisis Regresi Linear Berganda digunakan untuk mengetahui pengaruh antara satu variabel bebas terhadap variable terikat. Salah satu dari variable tersebut adalah adanya pengaruh suasana toko, lokasi dan promosi terhadap minat beli. Menurut Sugiyono (2014:263) persamaan regresi dalam penelitian ini adalah $\mathrm{Y}=\mathrm{a}+$ b1 $\mathrm{X} 1+\mathrm{b} 2 \mathrm{X} 2+\mathrm{b} 3 \mathrm{X} 3+\mathrm{e}$

\section{HASIL DAN PEMBAHASAN Uji Validitas}

Berdasarkan tabel hasil pengujian validitas bahwa dapat di ketahui bahwa nilai $r$ hitung semua item ( suasana toko, lokasi dan promosi ) lebih besar dari pada $r$ tabel dan semua bernilai positif.dengan demikian semua item yang ada dalam variabel dinyatakan valid.

\section{Uji Reliabilitas}

Berdasrkan tabel hasil pengujian reliabilitas di ketahui bahwa masing-masing variabel suasana toko, lokasi dan promosi 


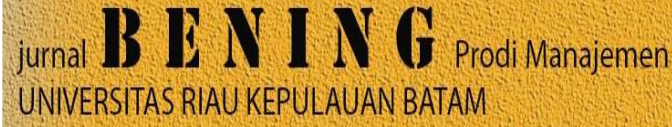

memiliki alpha hitung (alpha cronbach) lebih dari 0,60 yang berarti reliable.

Teknik Analisi Data

Uji Asumsi Klasik

Uji Normalitas

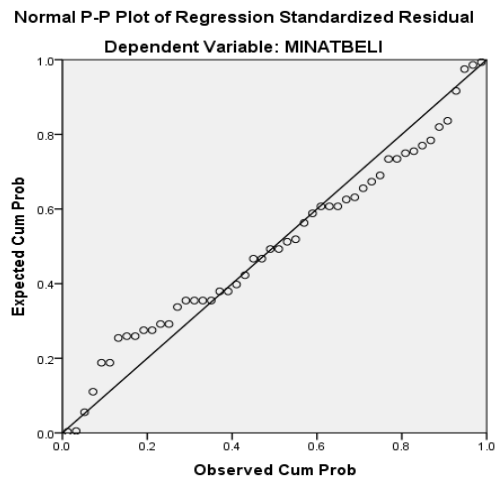

Hasil Uji Normalitas

Dapat disimpilkan bahwa titik tersebut berada dalam garis diagonal yang artinya model regresi normal Uji Multikolinearitas

Coefficients $^{\mathrm{a}}$

\begin{tabular}{|c|c|c|c|}
\hline & \multirow[t]{2}{*}{ Model } & \multicolumn{2}{|c|}{$\begin{array}{l}\text { Collinearity } \\
\text { Statistics }\end{array}$} \\
\hline & & $\begin{array}{c}\text { Toleranc } \\
\mathrm{e}\end{array}$ & VIF \\
\hline \multirow{4}{*}{1} & (Constant) & & \\
\hline & $\begin{array}{l}\text { SUSANATO } \\
\text { KO }\end{array}$ & .511 & 1.956 \\
\hline & LOKASI & .612 & 1.634 \\
\hline & PROMOSI & .513 & 1.950 \\
\hline
\end{tabular}

Hasil Uji Multikolinearitas

Dari tabel diatas semua varibel bebas memiliki nilai tolerance lebih besar dari 0,1 atau $10 \%$ dan nilai VIF kurang dari 10. Maka dapat disimpulkan bahwa tidak terjadi terjadinya asumsi klasik multikolinieritas antara variable bebas.

Uji Autokorelasi

\section{Model Summary ${ }^{b}$}

Volume 6 No. 1 Tahun 2019

P-ISSN 2252-5262

E-ISSN 2614-499

\begin{tabular}{|l|r|r|r|}
\hline \multirow{2}{*}{$\begin{array}{l}\text { Mo } \\
\text { del }\end{array}$} & \multicolumn{2}{|c|}{$\begin{array}{c}\text { Change } \\
\text { Statistics }\end{array}$} & \multirow{2}{*}{ Durbin-Watson } \\
\cline { 2 - 3 } & df2 & $\begin{array}{c}\text { Sig. F } \\
\text { Change }\end{array}$ & \\
\hline 1 & $46^{\mathrm{a}}$ & .000 & 1.958 \\
\hline
\end{tabular}

Diketahui nilai dari Durbin Watson 1,958 yang artinya bahwa adanya pengaruh antara variabel bebas dan variabel terikat. Uji Heteroskedastisitas

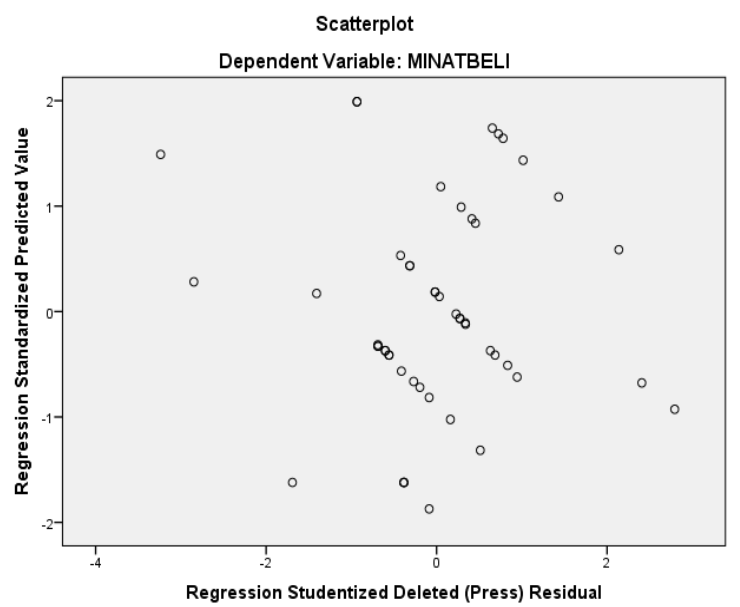

Hasil Uji Heteroskedastisitas

Berdasarkan gambar diatas dapat disimpulkan bahwa titik-titik diatas beracak tidak membentuk pola apapun yang artinya tidak terjadi heteroskedatisitas.

Analisis Regresi Linear Berganda Hasil Regresi Linear Berganda

Coefficients $^{a}$

\begin{tabular}{|c|c|c|}
\hline \multirow[t]{2}{*}{ Model } & \multicolumn{2}{|c|}{$\begin{array}{c}\text { Unstandardized } \\
\text { Coefficients }\end{array}$} \\
\hline & $B$ & Std. Error \\
\hline (Constant) & 3.354 & 2.412 \\
\hline $\begin{array}{l}\text { SUSANAT } \\
\text { OKO }\end{array}$ & .289 & .128 \\
\hline LOKASI & .329 & .113 \\
\hline PROMOSI & .237 & .128 \\
\hline
\end{tabular}




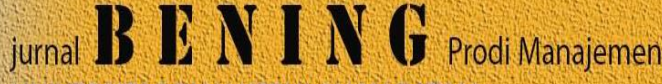 UNIVERSITAS RIAU KEPULAUAN BATAM}

Berdasarkan tabel di atas, maka dapat dibuat persamaaan regresi berganda sebagai berikut :

$\mathrm{Y}=3,354+0,298 \mathrm{X} 1+0,329 \mathrm{X} 2+0,237+$ e

Artinya :

$\mathrm{a}=3,354$ apabila suasana toko $(\mathrm{x} 1)$ lokasi (x2) dan promosi (x3), maka minat beli konsumen sebesar 0,354

$\mathrm{B} 1=0,289$ apabila suasana toko (x1) naik 1 (satu) satuan, maka minat beli konsumen akan naik sebesar 0,289 satuan.

B2 = 0,329 apabila lokasi (x2) naik 1 (satu) satuan, maka minat beli konsumen akan naik sebesar 0,329.

$\mathrm{B} 3=0,237$ apabila promosi (x3) naik 1(satu) satuan, maka minat beli konsumen akan naik sebesar 0,237.

Pengujian Hipotesis

Coefficients $^{\mathrm{a}}$

\begin{tabular}{|c|c|c|c|c|c|}
\hline \multirow[t]{2}{*}{ Model } & \multicolumn{2}{|c|}{$\begin{array}{l}\text { Unstandardi } \\
\text { zed } \\
\text { Coefficients }\end{array}$} & \multirow{2}{*}{$\begin{array}{c}\text { Stand } \\
\text { ardize } \\
d \\
\text { Coeffi } \\
\text { cients } \\
\text { Beta }\end{array}$} & \multirow[t]{2}{*}{$\mathrm{T}$} & \multirow[t]{2}{*}{ Sig. } \\
\hline & $B$ & $\begin{array}{l}\text { Std. } \\
\text { Error }\end{array}$ & & & \\
\hline $\begin{array}{l}\text { (Const } \\
\text { ant) }\end{array}$ & 3.354 & 2.412 & & $\begin{array}{r}1.3 \\
91\end{array}$ & $\begin{array}{r}.17 \\
1\end{array}$ \\
\hline SUSA & .289 & .128 & .298 & 2.2 & .02 \\
\hline $\begin{array}{ll} & \text { NATO } \\
1 & \mathrm{KO}\end{array}$ & & & & 54 & 9 \\
\hline $\begin{array}{l}\text { LOKA } \\
\text { SI }\end{array}$ & .329 & .113 & .353 & $\begin{array}{r}2.9 \\
15\end{array}$ & $\begin{array}{r}.00 \\
5\end{array}$ \\
\hline $\begin{array}{l}\text { PROM } \\
\text { OSI }\end{array}$ & .237 & .128 & .245 & $\begin{array}{r}1.8 \\
56\end{array}$ & $\begin{array}{r}.07 \\
0\end{array}$ \\
\hline
\end{tabular}

Hasil Uji t (Parsial)

Dari tabel di atas maka dapat dijelaskan sebagai berikut:

1. suasana toko: Nilai sig. $0,029<0,05$ menjelaskan bahwa variabel suasana toko secara parsial ada pengaruh yang signifikan terhadap minat
Volume 6 No. 1 Tahun 2019

P-ISSN 2252-5262

E-ISSN 2614-499

pembelian. Sehingga Hipotesis Pertama (H1) diterima.

2. Lokasi :Nilai sig. 0,005 $<0,05$ bahwa tata letak yang strategis secara parsial ada pengaruh yang signifikan terhadap minat pembelian. Sehingga Hipotesis Kedua (H2) diterima.

3. Promosi : Nilai sig. $0,070<0,05$ dapat dijelaskan bahwa variabel promosi secara parsial ada pengaruh yang siginifikan terhadap minat pembelian Sehingga Hipotesis Ketiga (H3) diterima.

Uji F (simultan)

Hasil Uji F (Simultan)

ANOVA $^{a}$

\begin{tabular}{|l|c|r|r|r|r|}
\hline Model & $\begin{array}{c}\text { Sum } \\
\text { of } \\
\text { Squar } \\
\text { es }\end{array}$ & Df & $\begin{array}{c}\text { Mean } \\
\text { Squar } \\
\mathrm{e}\end{array}$ & $\mathrm{F}$ & Sig. \\
\hline $\begin{array}{l}\text { Regr } \\
\text { essio } \\
\mathrm{n}\end{array}$ & 43.909 & 3 & $\begin{array}{r}14.63 \\
6\end{array}$ & $\begin{array}{r}21.8 \\
51\end{array}$ & $\begin{array}{r}.000 \\
\mathrm{~b}\end{array}$ \\
$\begin{array}{l}\text { Resid } \\
\text { ual } \\
\text { Total }\end{array}$ & 30.811 & 46 & .670 & & \\
\hline
\end{tabular}

Berdasarkan perhitungan di atas, $\mathrm{F}$ tabel sebesar 2,81. Karena nilai $\mathrm{F}$ hitung sebesar 21,851lebih dari pada nilai $\mathrm{F}$ 2,81maka dapat di tarik kesimpulan variable bebas suasana toko (X1), Lokasi (X2), dan promosi (X3) secara simultan berpengaruh positif dan signifikan terhadap minat pembelian (Y).

\section{PEMBAHASAN}

Pengaruh suasana toko terhadap minat beli

Pada hipotesis 1 bahwa suasana toko memiliki pengaruh yang signifikan terhadap minat beli konsumen. Dengan demikian konsumen selalu menginginkan suasana dan interior yang begitu nyaman bagi konsumen tersebut. Dalam penelitian 


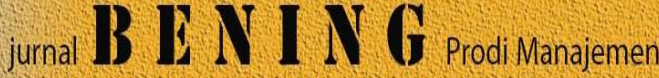 UNIVERSITAS RIAU KEPULAUAN BATAM}

ini konsumen yang menilai Toko Roti Morning bakery Kota Tanjungpinang memberikan Suasan ctoko yang baik dan berkualitas. Hasil ini membuktikan bahwa suasana toko berpengaruh secara signifikan terhadap minat pembelian.

Pengaruh lokasi terhadap minat beli

Pengujian pada hipotesis 2 menunjukan lokasi memiliki peranan penting atau pengaruh yang signifikan maupun hasil yang positif terhadap minat beli konsumen. Bahwa konsumen akan memilih lokasi toko yang mudah di cari dan strategis dalam tata letaknya agar mudah di jumpai dlam membeli suatu produk yang di inginkan konsumen tersebut. Dalam hal ini konsumen yang meniai bahwa akses, visabilitas, lalu lintas, tempat parkir dan lingkungan yang baik mempengaruhi minat beli konsumen yang lebih tinggi

Pengaruh promosi terhadap minat beli

Pengujian hipotesis 3 bahwa promosi memiliki pengaruh yang signifikan terhadap minat beli konsumen. Demikian pula dengan promosi, semakin baik usaha yang di promosikan maka semakin meningkat pula minat beli konsumen. Jadi promosi harus mampu menunjukan suatu produk yang selalu mempunyai ciri khas yang berbeda di khalayak konsumen agar konsumen penasaran dengan produk yang dipromosikan dan membuat konsumen membeli produk tersebut.

Pengaruh suasana toko, lokasi dan promosi terhadap minat beli

\section{DAFTAR PUSTAKA}

Adam, M. (2017). Effect of Price, Design and Location on Decision of Purchase and its Implication on Custemer Satisfaction. Economics, Commerce and Management, V(12), 345-353. Retrieved from http://ijecm.co.uk/

Anggreini Waloejan, N. (2016). The
Volume 6 No. 1 Tahun 2019

P-ISSN 2252-5262

E-ISSN 2614-499

Berdasarkan hasil uji ANOVA didapatkan $\mathrm{F}$ hitung sebesar 21,851dengan tingkat signifikan variable independen yang meliputi simultanatau bersama-sama mempengaruhi variable suasana toko (x1) lokasi (x2) dan promosi (x3) minat pembelian(y). Hasil ini menunjukkan bahwa dari ketiga variable tersebut adanya pengaruh dalam minat beli konsumen dalam suatu produk dan menunjukkan pengaruh yang signifikan dan positif.

\section{KESIMPULAN DAN SARAN Kesimpulan}

Dalam kasus seperti ini. Bahwa dapat dikatakan kesimpulan dari penelitian ini adalah adanya pengaruh suasana toko, lokasi dan promosi terhadap minat pembelian di toko roti Morning Bakery Batu 8 di Kota Tanjungpinang, baik secara parsial maupun secara simultan.

\section{Saran-saran}

Factor suasana toko, lokasi dan promosi Faktor suasana toko, lokasi dan terbukti berpengaruh signifikan terhadap minat beli di toko roti Morning Bakery Batu 8 di Kota Tanjungpinang memberikan perhatian lebih lagi dalam penataan suasana toko, lokasi yang begitu mudah di lalui dan strategis, dan promosi yang begitu baik hingga konsumen mudah mengenal produk yang ditawarkan tersebut.

Influence of Store Atmosphere on Consumer Purchase Decision at Kawan Baru Restaurant. Jurnal EMBA, 44(11), 1200-1219.

Arikunto, S. (2013). Prosedur Penelitian Suatu Pendekatan Praktik (15th ed.). Jakarta: Rineka Cipta.

Assauri, S. (2015). Manajemen Pemasaran 


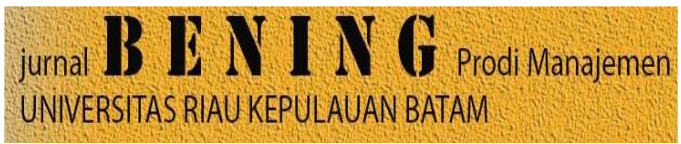

(1st ed.). Jakarta: PT Raja Grafindo Persada.

Banat, A., \& Wandebori, H. (2012). Store Design and Syore Atmosphere Effect on Customer Sales per Visit. Management and Behavioral Sciences, $v, 84-89$.

Gillani, F. (2012). Impact of Peer Pressure and Store Atmosphee on Puchase Intention. International Journal of Academic Research in Business and Social Sciences, 2(7), 323-332. Retrieved from http://www.hrmars.com/admin/pics/93 3.pdf

Hironaka, C., Zariyawati, M. A., \& DianaRose, F. (2017). The inFluence of Quality Products, Price, Promotion, and Location to Product Purchase Decision on Nitchi. Saudi Journal of Business and Management Studies, 2(4), 433-445. https://doi.org/10.21276/sjbms

Hussain, R., \& Ali, M. (2015). Effect of Stor Atmosphere on consumer Purchase Intention. International Journal of Marketing Studies, 7(2), 35-43.

https://doi.org/10.5539/ijms.v7n2p35

Julianti, N. L., Nuridja, M., \& Meitriana, M. A. (2014). Pengaruh Suasana Toko (Store Atmosphere) Terhadap Minat Beli Konsumen Pada Toserba Nusa Permai. Jurnal Pendidikan Ekonomi Undiksha, 4(1). Retrieved from https://ejournal.undiksha.ac.id/index.p hp/JJPE/article/view/4119

Kotler, P., \& Armstrong, G. (2008). Prinsip-Prinsip Pemasaran edisi 12 jilid 1. (A. Maulana, D. Barnadi, \& W. Harnadi, Eds.) (12 jilid 2). Jakarta: Erlangga.

Kotler, P., \& Armstrong, G. (2008). Prinsip-Prinsip Pemasaran edisi 12
Volume 6 No. 1 Tahun 2019

P-ISSN 2252-5262

E-ISSN 2614-499

jilid 2. (A. Maulana, D. Barnadi, \& W. Hardani, Eds.) (12 jilid 1). Jakarta: Erlangga.

Kotler, P., \& Keller, kevin lane. (2008). Manajemen Pemasaran edisi 13 jilid 2. (A. Maulana \& yayat sri Haryati, Eds.) (13 jilid 2). Jakarta: Erlangga.

Kouchekian, M., \& Gharibpoor, M. (2012). Investigation the Relationship Between Visual Merchandising and Customer Buying Decision Case. International Journal of Academic Research in Economics and Management Sciences, 1(2), 22263624. Retrieved from www.hrmars.com

Mahgfiroh, T., \& Yuniati, T. (2015). Pengaruh Store Atmosphere dan Location terhadap Minat Beli Dim Sum. Ilmu Dan Riset Manajemen, 4, 15.

Meldarianda, R., \& S, H. L. (2010). Pengaruh Store Atmosphere Terhadap Minat Beli Konsumen Pada Resoert Cafe Atmosphere. Bisnis Dan Ekonomi, 17(2), 97-108.

Po, F. L. R. (2011). Mining Purchasing Decision Rules from Service Ecounter Data Of Retail Chain Stores. Inf Syst E-Bus Manage, 9(101), 193-221. https://doi.org/10.1007/s10257-0100143-3

Pragita, A. A., Kumadji, S., Ilmu, F., Universitas, A., \& Malang, B. (2010). Pengaruh Store Atmosphere (Suasana Toko) Terhadp Emosi dan Dampaknya Kepada Keputusan Pembelian. Profit, 7, 1-11.

Priyatno, D. (2012). Cara Kiat Belajar Analisis Data dengan SPSS 20. (B. R. W, Ed.). Yogyakarta: CV. Andi Offset.

Sabrina, E.-B. (2014). The Influence of the Store Atmosphere on the Consumer 
jurnal $\mathbf{B} \rrbracket \mathcal{N} I G$ Prodi Manajemen

UNIVERSITAS RIAU KEPULAUAN BATAM

Behavior. Mediterranean Journal of Social Sciences, 5(8), 229-235. https://doi.org/10.5901/mjss.2014.v5n $8 \mathrm{p} 229$

Sudaryono. (2016). Manajemen Pemasaran Teori dan Implementasi. (F. Sigit, Ed.). Yogyakarta.

Sugiyono. (2013). Metode Penelitian Pendidikan (Pendekatan Kuantitatif, Kualitatif, dan $R$ \& D). Bandung: ALFABETA, cv.

Sugiyono. (2016). Metode Penelitian Kuantitatif, Kualitatif $R \quad \& \quad D$. Bandung: ALFABETA, cv.

Suhartono, D., Djatnika, T., \& Triyuni, N. N. (236AD). Ritel Pengelolaan dan

Pemasaran. (S. F, Ed.). Bandung: ALFABETA, cv.

Sujarweni, V. W. (2015). Metodologi Penelitian Bisnis dan Ekonomi. Yogyakarta: Pustakabarupress.

Sunyoto, D. (2011). Analisis Regresi dan
Volume 6 No. 1 Tahun 2019

P-ISSN 2252-5262

E-ISSN 2614-499

Uji Hipotesis. (K. Awalamsyah, Ed.). Yogyakarta: CAPS.

Sunyoto, D. (2011). Metodologi Penelitian Ekonomi. (Destyan \& T. Admojo, Eds.). Yogyakarta: CAPS.

Sunyoto, D. (2014). Dasar-Dasar Manajemen Pemasaran (Konsep, Strategi, dan Kasus). (Sugeng, Yunita, T. Admojo, \& Tika, Eds.) (1st ed.). Yogyakarta: CAPS.

Syahputra, D. E. (2015). Pengaruh Store Atmosphere, Harga dan Lokasi Terhadap keputusan Pembelian Ore Premiun Store. Journal Ilmu Dan Riset Manajemen, 4, 1-20.

Tongkukut, S. H. J. (2016). Analisis Tingkat Pencahayaan Ruang Kuliah Dengan Memanfaatkan Pencahayaan Alami Dan Pencahayaan Buatanklorofil Pada Beberapa Varietas Tanaman eum a Jurusan. Jurnal Mipa Unsrat, 5(2), 108-112. 